\title{
Technology-enhanced Learning for Promoting Technical and Social Competences in Hydrological Science
}

\author{
Feliciana Licciardello ${ }^{1}$ (D) . Simona Consoli ${ }^{1}$. Giuseppe Cirelli ${ }^{1}$. Carlos Castillo ${ }^{2}$. \\ Elvira Fernández-Ahumada ${ }^{3}$ (D) . Jesús Montejo-Gámez ${ }^{4}$ (D) . Encarnación V. Taguas ${ }^{2}$
}

Accepted: 20 March 2021 / Published online: 4 April 2021

(c) The Author(s) 2021

\begin{abstract}
This paper explains and analyses a virtual gamification experience developed by a teaching group from the University of Catania (Italy) and the University of Cordoba (Spain). A competition based on professional tasks about hydrological planning was implemented in two subjects on Hydrological Sciences. The teaching experience was designed to improve the acquisition of technical knowledge and skills needed for hydrological studies, promote the management of ICT and increase international cooperation between different universities; all aimed at making students more employable. The experience is transferable to different academic levels. Following the philosophy of soccer leagues, the students solved and presented the exercise by teams of two students. Through videoconference, the presentation and the explanation were done so the fans in each country supported their teams. The students found it a very challenging experience but at the same time, some of them were aware of their needs of improving technical knowledge, particularly Geographical Information Systems, and English language skills. Updating of tools and the schedule within the different academic calendar were their main organization handicaps. The main outcome of the presented experience is that social energy and enthusiasm associated to popular activities such as soccer led to improve the interest and the motivation of the students in challenging technical contents as well as teamwork and language transversal competences.
\end{abstract}

Keywords Social and technical competences $\cdot$ Hydrological Sciences $\cdot$ International teaching experience $\cdot$ Gamification

Feliciana Licciardello

flicciar@unict.it

1 Department of Agriculture, Food and Environment (Di3A), University of Catania, Via Santa Sofia, 100-95123 Catania, Italy

2 University of Cordoba, ETSIAM, Córdoba, Spain

3 Department of Mahtematics, Faculty of Education Sciences, University of Cordoba, Córdoba, Spain

4 Departament of Mathematics Education, Faculty of Education Sciences, University of Granada, Granada, Spain 


\section{Introduction}

The challenge of transforming the teaching-learning processes to train professionals adapted to the new times has evidenced the need to promote scenarios allowing the development of competencies such as adaptivity, autonomy, self-learning, teamwork or anticipation, considered, according to Uskov et al. (2018), characteristic of smart classrooms.

In this context, activities in which students work with real problems take on special relevance. For that aim, it is important to design learning that combines both real and virtual learning environments (Zhu et al., 2016) and where technology-enhanced-learning may play an important role. In this line, there are innovative learning initiatives including learning-by-doing, flipped classroom, game-based learning, adaptive teaching, or collaborative learning, among others, whose outcomes are demonstrating their benefits and contribution to what is called smart pedagogy.

These new trends in education make a good deal of sense in the field of engineering and particularly in water planning, which has become a globalized issue, is changing at an unprecedented rate because it deals with a critical resource for humans, and suitable characterization, prediction and response to threats are required. The evaluation of hydrological risk assessment and modelling studies are vitally important, especially in Mediterranean countries, due to the extreme irregularity of the water regime. Flood control studies are needed to protect infrastructures close to rivers against periodic extreme events. In contrast, dams are required to store water for dry periods. In addition, there is a high degree of uncertainty associated with the impact of climate change. When these issues are analysed in engineering studies, students encounter learning difficulties regarding the theoretical concepts of hydrology, the management of different sources of information (topographical features, meteorological data and land use, among others) and the use of tools such as the Geographical Information Systems. Under this scenario, smart pedagogies provide educators with strategies to elicit students' development of competences.

On one hand, cooperative learning in engineering degrees has demonstrated its capacity to improve training in technical, personal and contextual competences (De los Ríos et al., 2010; Wan Alwi et al., 2012). The use of virtual reality to implement such teaching strategies has proven to be positively perceived by students (Fernández-Ahumada et al., 2020). These methodological approaches also allow students to develop critical thinking and improve social skills, by sharing or defending their ideas. At the same time, aspects such as creativity, autonomy, life-long learning and the capacity of analysis are strengthened when the students work on common scenarios or real cases they may face in the future as professionals (Göl \& Nafalski, 2007; Schaf et al., 2009; Rodríguez-Donaire \& Amante, 2012; Redel et al., 2014).

On the other hand, numerous experiences in education have demonstrated the usefulness of gamification to enable students to familiarize themselves with real problems in engineering (Deshpande \& Huang, 2011; Nag et al., 2013), as well as in other fields (Randall et al., 1992). The use of games based on sports can be a motivating way of illustrating concepts in different disciplines. Rydakob et al. (2010) selected a range of games based on parachute jumps, skating, free-falling and running to explain the basic laws of theoretical mechanics, including examples which focused the students' attention on different academic disciplines. Various reviews and empirical papers show that, in education/learning contexts, gamification has mostly positive effects in terms of increased motivation, participation and enjoyment of learning tasks (Hamari et al., 2014; Koivisto \& Hamari, 2019; Pertegal-Felices et al., 2020). In the field of computer engineering education, where 
research on gamification abounds, a positive impact of gamification on student knowledge has also been detected (Kasahara et al., 2019; Venter, 2020). Among other advantages, Falavigna et al. (2016) highlight that gamification provides an opportunity to present contents integrated in a teaching activity shared with students; although, as Dominguez et al. (2013) point out, designing and implementing a successful gamification experience requires a great effort. Hamari et al. (2014) also underline, among the negative outcomes to which attention should be paid, the difficulties in evaluating tasks and the effects of increased competition.

As exposed above, the proper combination of elements of gamification and the use of technology may give rise to smart teaching strategies that promote the development of students' professional competencies, not only the technical but also the social ones, in order to address real projects.

In this paper, some elements of gamification have been considered. The authors understand gamification as "the use of game design elements in non-gaming contexts" as described by Deterding et al. (2011). These authors point out that gaming is not the same as playing, since gaming implies the use of well-defined rules and competition to achieve objectives, as opposed to playing, which is understood as a freer and more improvised form of expression. In the educational context, we understand gamification as the introduction of a system of learning objectives for the achievement of which students must compete by respecting certain rules. In this paper, elements of gamification such as levels and rewards are reflected which, together with leaderboards, are considered to be the most used in the field of engineering education (Koivisto \& Hammari, 2019; Venter, 2020).

Furthermore, approaching this activity in a context of collaboration between universities adds learning opportunities for students. The collaboration between universities of different countries to share similar projects and teaching methodologies is an essential part of the Bologna Process. International teaching experiences can help to develop different skills (including foreign language learning), social competences and employability features among their students, and thus facilitate their access to the labour market.

In this paper, an educational experience including components of the above-mentioned methodologies is presented. It aimed at improving students' acquisition of technical knowledge and skills needed for hydrological studies and increasing international cooperation between two universities, through a competition devised along the lines of the European soccer leagues, which have an enthusiastic and competitive following in Italy and Spain. The research deals with the open question of analyzing the impact of the experience on students' perception.

The analysis aims at exploring both the usefulness of a teaching experience with elements of technology-enhanced learning and how the students felt about it. Concretely, the research question to answer is as follows: How students perceive the implementation of this teaching experience to develop professional and technical competences related to water planning?

\section{Methodology}

\subsection{Participants and Teaching Experience}

We chose two courses for this teaching experience: a course entitled "Water Resources Management in Agriculture" at the University of Catania (Italy) and a course entitled 
"Software and Tools in Engineering Projects" at the University of Cordoba. A total of 39 students were involved in the first phase of the two-year study: 23 in Spain and 16 in Italy.

The first course belongs to the second semester of the 4th year of the degree in Civil Engineering, with 60 hours of lectures, whereas the latter belongs to the 4th year of the degree in Forestry Engineering, with 45 hours of lectures. The courses had content and competences in common. Figure 1 shows a summary of the experience.

The target competences of the instruction were the following: (i) teamwork; (ii) cooperative learning and the use of ICT in order to improve adaptation to technological, social and economic changes; (iii) communication to share knowledge between students in different social environments; (iv) social and environmental commitment when carrying out professional activities; and (v) innovation, creativity, leadership and critical thinking needed to solve problems.

The professional task to carry out during the experience is based on the Curve Number method developed by the Soil Conservation Service (1972), whose objective is to calculate the runoff of a catchment and the maximum peak flow to provide measurements for flood control infrastructures. Firstly, the students were put into groups of two or three and taught the theoretical concepts, and then they were given a common practical case to solve (Figure 2).

The cartographical information such as maps and the digital elevation model were given to generate the catchment drainage area and the channel slope and length, while the aerial ortophotography and soil map allowed them to distinguish the land uses, soil types and management. 6-hour practical sessions were given in the use of Geographic Information Systems for evaluating the physical features of land. The main objective was to determine the drainage area and the concentration time of the catchment as well as its Curve Number. The meteorological data of precipitation at the study site were used to adjust the intensityduration-frequency relationships and to create the input hyetograph of total precipitation

OBJECTIVE: Acquisition of technical knowledge skills in hydrological studies through a competition, following the competition set-up of the European soccer leagues which are extremely popular in Italy and Spain

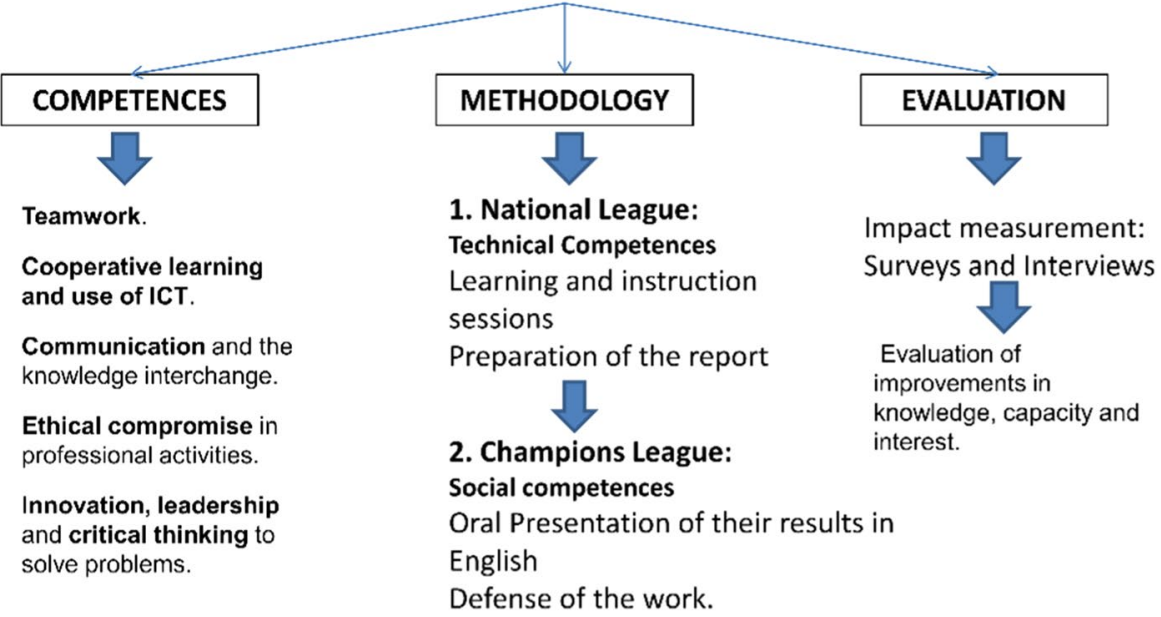

Fig. 1 Summary of the experience: objectives, competences, methodological structure and assessment procedure 


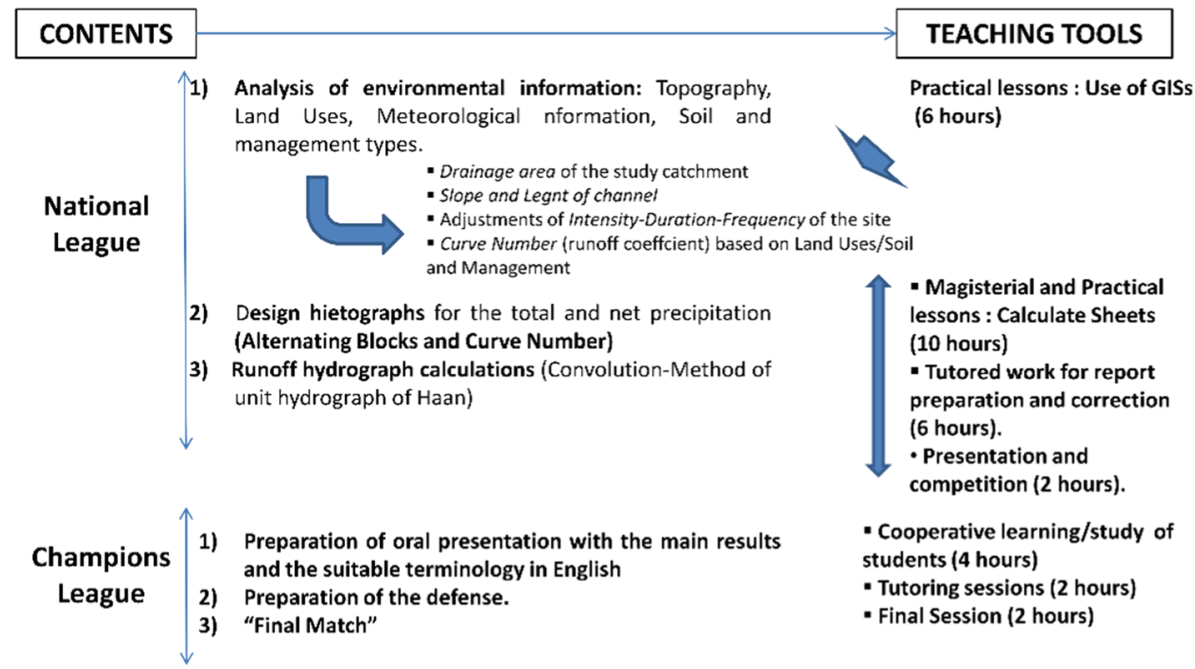

Fig. 2 Details of the methodology followed: technical and humanistic/social contents and temporal organization and session types

following the methodology of alternating blocks. Finally, after calculating the hyetograph of net precipitation through the Curve Number approach, the students had to calculate the output hydrograph and the peak flow for the project (Figure 2). For this part, 16 hours were required for the theoretical and practical lessons, as well as the tutoring work required to prepare the report.

For the first stage ("National League"), the students from each University presented their projects to their tutor. The tutors and students agreed on the best teams, and these played the "Champions League", which took place via video conferencing. This two-phase approach shows examples of gamification elements such as levels and leaderboard. An international committee composed of Spanish and Italian tutors decided on the winning team on the basis of the accuracy of results, the capacity to explain and defend the work in English and the quality of the presentation. The prize for the winners in each country included a certificate of participation in international conferences and a winner's certificate. In this case, the gamification elements used were the rewards.

\subsection{Data Collection and Analysis Procedures}

In order to evaluate the impact of the teaching experience on the students' perceptions, quantitative and qualitative analyses were performed (Alaminos-Chica et al., 2006).

Quantitative data were obtained through two questionnaires: one of them before (pretest) and another one after the course (post-test). Each questionnaire had three five points Likert-scale questions (1: total disagreement, 5: full agreement):

1. Rate your level of knowledge (or "improvement" after the course) of engineering projects related with water management.

2. Do you feel capable (or "more capable" after the course) of carrying out a hydrological study for controlling floods or managing resources? 
3. Rate your level of interest (before and after the course) in Hydrology.

The answers to these questions provided the scores of three variables per questionnaire: Knowledge (connected to question (1), Competence (connected to question (2) and Interest (connected to question (3). In order to have a whole idea of students' perceptions about the course, a fourth variable was also calculated: Global valuation, whose values are the average of the three other ones. Therefore, 8 variables were considered for the analyses: 4 in the pre-test and 8 in the post-test.

Also, t-tests were applied to check the significance of the difference in the survey results before and after the course.

Qualitative analysis was carried out through two interviews with all the participants (students and professors). The interviews had flexible scripts to check the provided answers from the questionnaires and to complete the impact interpretation of the learning experience. All the opinions were transcribed to texts which were reviewed and organised to provide main strengths and weaknesses of the course according to the students and the professors.

\section{Results}

\subsection{Quantitative Analysis}

Table 1 shows the descriptive statistics of the results for the students who answered the questions and also the variation of the score before and after the course in both countries.

Regarding the initial evaluation (pre-test), the scores of the Knowledge, Competence and Interest were around 2.50, 3.26 and 3.74, respectively. Thus, the global valuation of students' perceptions about their skills had a score of 3.17. In this first valuation, differences between Spanish and Italian perceptions were less than 0.5 in all the variables.

Regarding the final evaluation (post-test), the variables Knowledge, Competence and Interest obtained scores around 3.54, 4.06 and 4.51, respectively, with a global valuation

Table 1 Descriptive statistics for the variables analysed for the Italian students, the Spanish students and all together

\begin{tabular}{|c|c|c|c|c|c|c|}
\hline & \multicolumn{2}{|l|}{ Spanish } & \multicolumn{2}{|l|}{ Italian } & \multicolumn{2}{|l|}{ Together } \\
\hline & Mean value & s.d. & Mean value & s.d. & Mean value & s.d. \\
\hline \multicolumn{7}{|l|}{ Pre-test } \\
\hline Knowledge & 2.59 & 0.91 & 2.38 & 0.5 & 2.50 & 0.76 \\
\hline Competence & 3.35 & 0.83 & 3.13 & 0.81 & 3.26 & 0.82 \\
\hline Interest & 3.61 & 0.78 & 3.94 & 0.77 & 3.74 & 0.79 \\
\hline Global val. & 3.19 & 0.93 & 3.15 & 0.95 & 3.17 & 0.94 \\
\hline \multicolumn{7}{|l|}{ Post-test } \\
\hline Knowledge & 3.57 & 0.68 & 3.50 & 0.52 & 3.54 & 0.61 \\
\hline Competence & 4.19 & 0.93 & 3.86 & 0.36 & 4.06 & 0.76 \\
\hline Interest & 4.33 & 0.80 & 4.79 & 0.43 & 4.51 & 0.70 \\
\hline Global val. & 4.03 & 0.86 & 4.05 & 0.70 & 4.04 & 0.80 \\
\hline
\end{tabular}

"s.d." refers to the standard deviation. 
around 4.04. In this case, no great differences were found between Spanish and Italian perceptions. To sum up, descriptive statistics suggests that the course provokes higher scores in all the variables. Also, the global valuations of Spanish and Italian students are similar to each other.

Figure 3 shows the distribution of frequencies along the different questions in the two countries, both in the pre-test and in the post-test. Before the course, $14 \%$ and $0 \%$ of students in Spain and Italy, respectively, produced scores greater than 3 in the variable Knowledge. After the course in both countries the score for Knowledge increased 67\% in Spain (a high/very high level of knowledge), and 50\% in Italy (a high level of knowledge). The global value increased more in Spain (75\%) than in Italy (47\%).

Question 1 - knowledge level

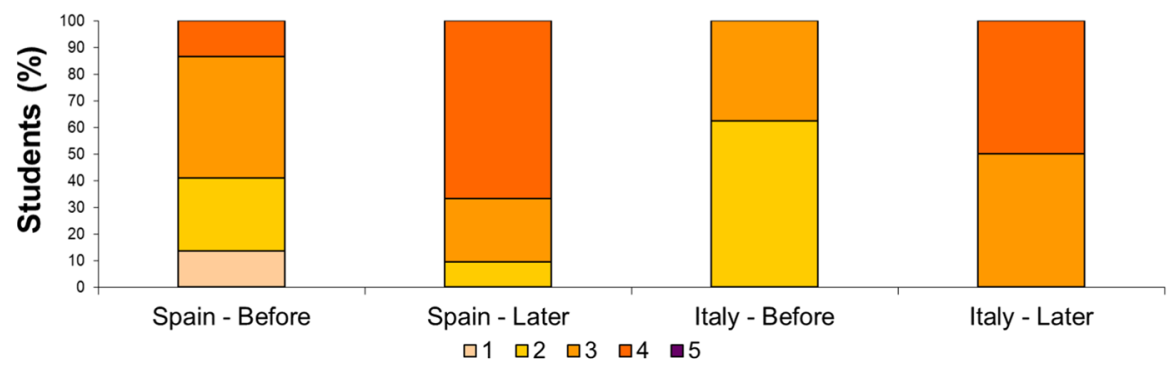

Question 2 - capability

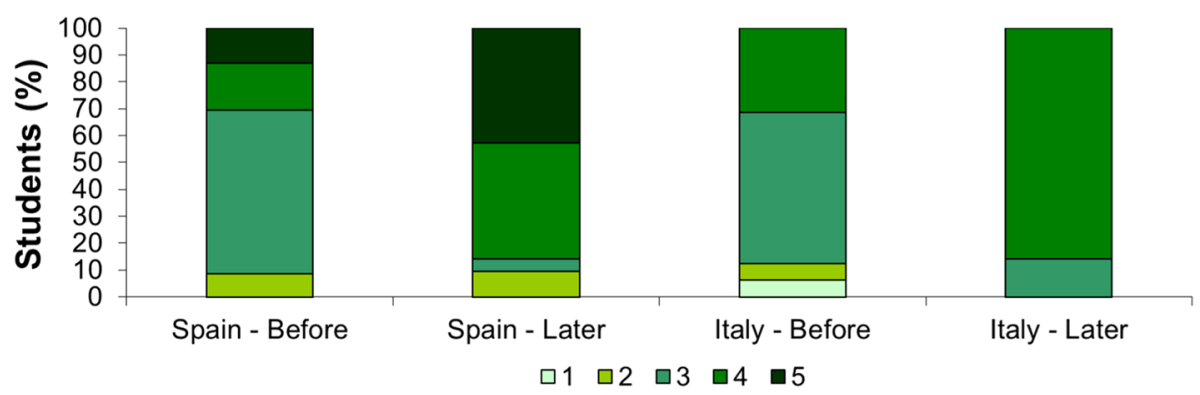

Question 3 - interest

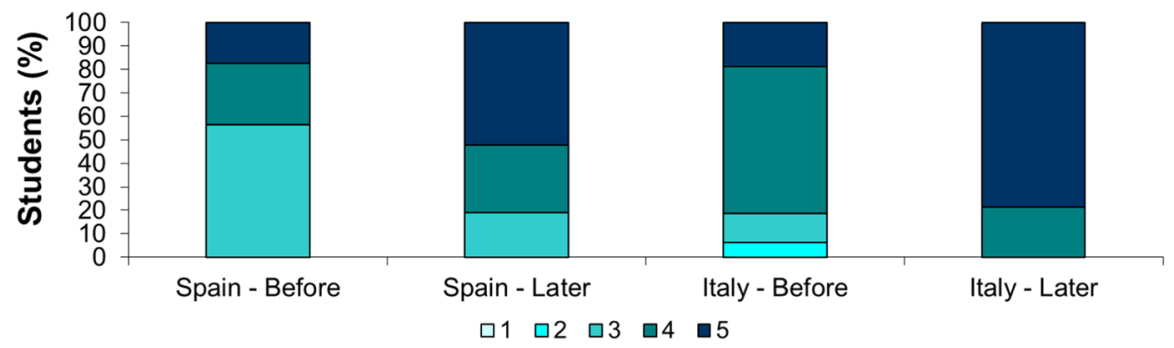

Fig. 3 Percentages of students who chose the answers with the different score before and after the course in Spain and Italy 
Concerning the variable Competence, about $70 \%$ of the students in both countries thought before the course that they were not able to carry out a hydrological study for controlling floods or managing resources; after the course, about $86 \%$ in both countries felt more comfortable with these kinds of studies, even if most of them said they still needed more experience. The mean score increased for both countries by about $25 \%$.

About the variable Interest, all the students involved in the course in both countries showed, at the beginning, interest in learning at least the basics of Hydrology $(94 \%$ in Italy and $100 \%$ in Spain). After the course, the level of interest was higher/much higher than before for most of the students (81\% in Spain and $100 \%$ in Italy) and the mean score increased in both countries, albeit slightly less (about 20\%) compared with the other questions, due to the fact that there was some interest before.

Regarding the t-tests, Table 2 exposes significant differences (p-value less than 0.01 in one case and less than 0.001 in the rest) for each of the three questions, both when considering Spain and Italy separately and together. The values of Cohen's d, statistic which measures to what extent the impact of the course was important, show that for Spanish students the impact was large and for Italian students it was medium, according to descriptors proposed by Cohen (1988) and expanded by Sawilowsky (2009).

\subsection{Qualitative Analysis}

The main strengths mentioned by the students were summarised in Table 3. It is worth noting how the motivation and challenge involved in an international competition, as well as the consolidation of certain concepts in hydrology and the formal recognition obtained and the practical projects carried out during the course were the most highlighted aspects by the students. As for weaknesses, the following aspects were emphasised: (i) lack of previous knowledge to address the practical case as a result of different backgrounds derived from the teaching program of each University; (ii) lack of English language skills and (iii) the extra-effort to face voluntary activities which are not essential to pass the subject. In the case of the University of Cordoba, most students enroll in this optional subject - because it is eminently practical and due to the great use of ICTs. Loss of motivation appears as a result of many concepts in Hydrology can result quite abstract as well as their interrelationships, especially when mathematical models are applied.

As far as the tutors were concerned (Table 3), the main strengths were the positive and enthusiastic reaction of the participants, the improvement in the students' technical knowledge and the acquisition of soft skills related with the oral expression, teamwork and the cooperation with other universities. It is relevant to underline how the practical work carried out was demanded to pass, however the form of presentation and the competition was

Table 2 Results of the t-test and effect sizes

\begin{tabular}{|c|c|c|c|c|c|c|}
\hline & \multicolumn{2}{|l|}{ Spanish } & \multicolumn{2}{|l|}{ Italian } & \multicolumn{2}{|l|}{ Together } \\
\hline & $p$-value & Cohen's d & $p$-value & Cohen's d & $p$-value & Cohen's d \\
\hline Knowledge & $<0.001 * *$ & 0.82 & $<0.001 * *$ & 0.52 & $<0.001 * *$ & 0.70 \\
\hline Competence & $<0.001 * *$ & 0.90 & $<0.01 *$ & 0.65 & $<0.001 * *$ & 0.80 \\
\hline Interest & $<0.001 * *$ & 0.81 & $<0.001 * *$ & 0.65 & $<0.001 * *$ & 0.76 \\
\hline Global val. & $<0.001 * *$ & 0.91 & $<0.001 * *$ & 0.85 & $<0.001 * *$ & 0.88 \\
\hline
\end{tabular}


Table 3 Summary-list of the main strengths and weaknesses derived from the experience

\begin{tabular}{|c|c|c|}
\hline Group & Main strenghts & Main weaknesses \\
\hline Students & $\begin{array}{l}\text { Motivating and } \\
\text { challenging } \\
\text { Complete analysis } \\
\text { of different } \\
\text { concepts of } \\
\text { Hydrology } \\
\text { Interesting merits } \\
\text { A practical activity } \\
\text { where interest- } \\
\text { ing ICTs were } \\
\text { handled }\end{array}$ & $\begin{array}{l}\text { Extra-work (time consuming } \\
\text { activity) } \\
\text { Problems to meet and collaborate } \\
\text { with the peers } \\
\text { Difficulties to handle Geographi- } \\
\text { cal Information Systems or lack } \\
\text { of some previous knowledge } \\
\text { Difficulties with a foreign lan- } \\
\text { guage }\end{array}$ \\
\hline Professors & $\begin{array}{l}\text { Rewarding reaction } \\
\text { of students } \\
\text { knowledge and } \\
\text { soft skills (oral } \\
\text { expression and } \\
\text { teamwork) }\end{array}$ & $\begin{array}{l}\text { Differences in the scholar calendar } \\
\text { Extra work for translating and } \\
\text { preparing a suitable English } \\
\text { material for both groups of } \\
\text { students } \\
\text { Extra work to find a suitable room } \\
\text { and preparation arrangements } \\
\text { Difficulties to motivate the } \\
\text { participation of the students in } \\
\text { "extra-activities" due to excess } \\
\text { of homework, exams, etc. }\end{array}$ \\
\hline
\end{tabular}

the key to promote a higher degree of involvement and motivation of the students, who could adopt the role of players or as fans of their team when they failed.

The perceived weaknesses were mainly related with organization and the extra work required apart from the difficulties to motivate the participation in a context of scarce immediate reward for the students. In both subjects, loss of motivation appears as a result of many concepts in Hydrology can result quite abstract as well as their interrelationships, especially when mathematical models are applied. The use of ICTs, which is well-valued and attractive for the students, can compensate the discouragement associated to the work field difficulty.

\section{Discussion and Conclusion}

This paper describes a teaching experience based on smart strategies to enhance undergraduate students' competencies, in a shared international virtual gamification strategy. This learning experience improved the undergraduate engineering students' perceptions on their own competences, as well as interest on water planning (Figure 4). It is worth noting how the weighted scores on knowledge and capability were similar in both countries before the teaching experience, however, Italian students who were initially "more interested" reached the highest scores.

The results showed that, as in similar experiences (Wan Alwi et al., 2012; Hamari et al., 2014; Koivisto \& Hamari, 2019; Pertegal-Felices et al., 2020; Venter, 2020), the degree of motivation among students and teachers increased. In particular, the students experienced that their knowledge increased after the course. They also felt that their capacity to carry out a hydrological study after the course had improved, even if the resulting mean score was lower than for the first question. This means that they need more practical knowledge 
Q1-Knowledge Q2-Capability Q3-Interest

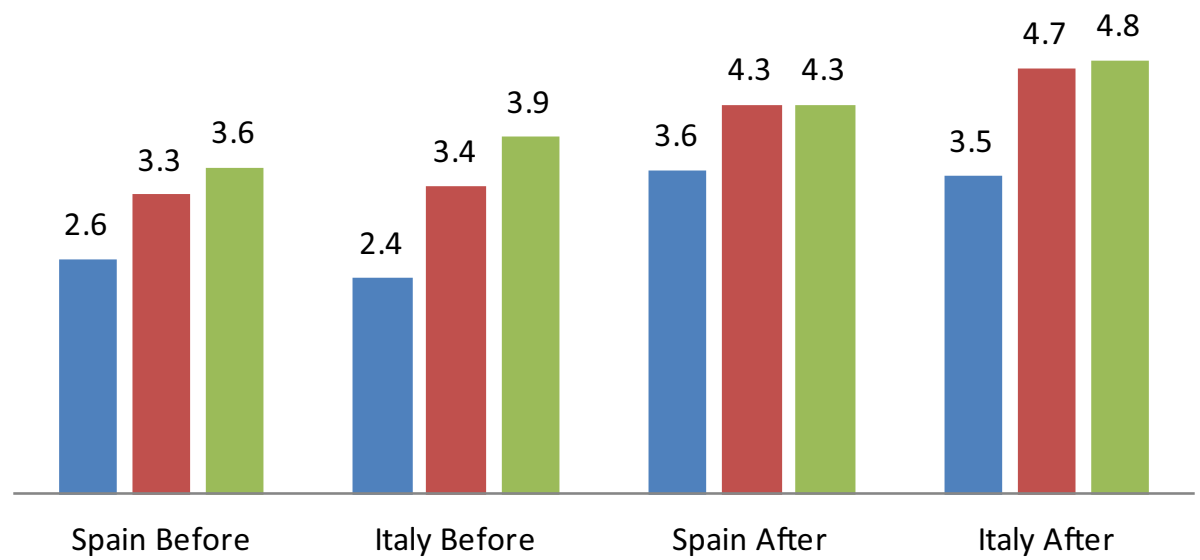

Fig. 4 Weighted scores (1-5) obtained for the question about knowledge, capability and interest (Q1-Q3) before and after the teaching experience in Spain and Italy

to feel completely comfortable when carrying out a hydrological study for controlling floods or managing resources. Nevertheless, although interest in studying hydrology was high before the course, it increased even more after the course. The fact that the mean evaluated score for all the questions increased by $34 \%$ for Spain and $29 \%$ for Italy after the course proves that there was a generally positive evaluation of the experience. Other studies can be compared with our case: for instance, Belloti et al. (2014) analyzed the impact of different "serious games" used in business schools in Europe and highlighted that the "fun element" led to an improvement in both student motivation and their capacity for analysis in entrepreneurship.

On the other hand, considering the second stage of the course ("The Champions League"), those students from each country who played in the international final by videoconference were capable of explaining and defending their work in English, which was a highly rewarding experience, combined with the opportunity to participate in international conferences and receiving a winner's certificate. Similar findings were reported by Dominguez et al. (2013), in the context of a transversal university course, indicating that "gamification can have a great emotional and social impact on students, as reward systems and competitive social mechanisms seem to be motivating for them". On the other hand, Remon et al. (2020) also observed the increase students' awareness about the existence of intrinsic sociocultural differences related to language when they worked in international pairs with students of Chemical engineers on new bio-refinery concepts.

Despite the fact that the students commented "off the record" that the game style encouraged them to dedicate more of their free time to the project (as other authors have noticed, e.g. Ross et al., 2014) the weaknesses expressed were mainly connected with organization and the extra work involved (as also reported by Domínguez et al., 2013), as well as with difficulties related to using the Geographical Information Systems and foreign language skills. More stuff and training on this kind of systems would overcome the mentioned weaknesses.

One of the strengths of this work is that it has implemented an experience that can be considered as a collective gamification. This idea has been pointed out by Koivisto and 
Hamari (2019) as one of the future lines whose possibilities should be further explored from the point of view of educational research. In fact, European soccer leagues and/ or World Cup spirit are understood in countries all over the world which can be helpful in numerous international educative contexts to encourage the effort in difficult subjects. The benefits of internationalizing engineering education have been identified by authors such as Beddoes et al. (2010), Diaz-Lantada \& Sevillano (2017) and Remon et al. (2020), keys to provide comparative assessments, joint curriculum development, pooling of academic expertise and economies of scale, dissemination of "best practices," setting and promoting international standards and forums for and broadening the perspectives of researchers, students, and faculty, among others.

On the contrary, some limitations of this work are related to the so-called novelty effect (Kasahara et al., 2019). Evidently, the experience was designed to improve the learning. Therefore, similar studies are then needed to analyse the long-term effect of such experiences. Another limitation of this research concerns external validation of the results, which is somehow an intrinsic feature of this kind of experiences: they can be difficult to reproduce in other settings (Kasahara et al., 2019). In this sense, it is important that sport rules are known and "popular" for the participants. In addition, the authors believe that efforts should be made to develop tools that allow the teacher's work and analysis to be automated. As for the learning results compared with other academic years, the additional improvement of social competences was definitely more enriching for the students whereas the knowledge contents were exactly the same. Authors such as Grasso and Martinelly (2010) also underlined the need to integrate knowledge across different disciplines in engineering to deal with complex problems and better serve humanity.

Finally, we would like to highlight how the use of a positive energy associated to social life (soccer in this case) allowed us to refocus student interests. We consider that not are only these aspects worthy for improving technical knowledge in Hydrological Sciences, but they also lead to enhance humanistic competences in any type of teaching. Policy making on educational strategies should encourage positive attitudes on hard sciences to encourage effort and openness for cooperative learning basing on micro level experiences as the obtained in the present study.

Acknowledgements The authors would like to thank Simon Armour for his invaluable help in revising the paper. The authors also thank the involved students for their participation and M. José Palazón, Rafael Pimentel, Manuel Rosa and M. Jose Polo for their support in the final game of the second year.

Funding Open access funding provided by Università degli Studi di Catania within the CRUI-CARE Agreement.. This project was supported by the University of Cordoba Teaching Innovation Project 2004-2014 entitled "Adquisición de competencias técnicas y humanísticas y estandarización internacional de currículos en la enseñanza de proyectos de ingeniería rural: llevando la pasión por el fútbol a casos prácticos de Hidrología." ("Acquiring technical and humanistic competences and the international standardization of curricula in teaching rural engineering projects: using a passion for football in practical cases of Hydrology").

Data Availability Data are available in the teaching platform of the Universities involved and they can ask Dr F. Licciardello (flicciar@unict.it) and Dr. E.V. Taguas (evtaguas@uco.es).

\section{Declarations}

Conflicts of interest No financial interest or benefit that has arisen from the direct applications of the present research. 
Open Access This article is licensed under a Creative Commons Attribution 4.0 International License, which permits use, sharing, adaptation, distribution and reproduction in any medium or format, as long as you give appropriate credit to the original author(s) and the source, provide a link to the Creative Commons licence, and indicate if changes were made. The images or other third party material in this article are included in the article's Creative Commons licence, unless indicated otherwise in a credit line to the material. If material is not included in the article's Creative Commons licence and your intended use is not permitted by statutory regulation or exceeds the permitted use, you will need to obtain permission directly from the copyright holder. To view a copy of this licence, visit http://creativecommons.org/licenses/by/4.0/.

\section{References}

Alaminos-Chica, A., \& Castejón-Costa, J. L. (2006). Elaboración, análisis e interpretación de encuestas, cuestionarios y escalas de opinión. . Instituto de Ciencias de la Educación. Universidad de Alicante.

Beddoes, K. C., Jesiek, B. K., \& Borrego, M. (2010). Identifying opportunities for collaborations in international engineering education research on problem- and project-based learning. Interdisciplinary Journal of Problem-based Learning, 4(2), 7-34.

Bellotti, F., Berta, R., De Gloria, A., Lavagnino, E., Antonaci, A., Dagnino, F., Ott, M., Romero, M., Usart, M., \& Mayer, I. S. (2014). Serious games and the development of an entrepreneurial mindset in higher education engineering students. Entertainment Computing, 5(4), 357-366.

Cohen, J. (1988). Statistical power analysis for the behavioral sciences. (2nd ed.). Lawrence Earlbaum Associates.

De los Ríos, I., Cazorla, A., Díaz-Puente, J. M., \& Yagüe, J. L. (2010). Project-based learning in engineering higher education: two decades of teaching competences in real environments. Procedia Social and Behavioral Sciences, 2, 1368-1378.

Deshpande, A. A., \& Huang, S. H. (2011). Simulation games in engineering education: A state-of-the-art review. Computers Application in Engineering Education, 19(3), 399-410.

Deterding, S., Dixon, D., Khaled, R., \& Nacke, L. (2011). From game design elements to gamefulness: defining gamification. In Proceedings of the 15th International Academic MindTrek Conference: Envisioning Future Media Environments (pp. 9-15). ACM.

Diaz Lantada, A., \& Marquez Sevillano, J. D. J. (2017). Towards global engineers: challenges and strategies for promoting international mobility in engineering education. International Journal of Enginerring Education, 33, 1995-2007.

Domínguez, A., Saenz de Navarrete, J., Marcos, De., Sanz, Fernández, \& Pagés, Martínez Herráiz. (2013). Gamifying learning experiences: Practical implications and outcomes. Computers \& Education, 63, 380-392.

Falavigna, L., Duarte, J. L., Dittmar, A., \& Pizzolato, M. (2016). Benefits of educational games as an introductory activity in industrial engineering education. Computers in Human Behavior, 58, 315-324. https://doi.org/10.1016/j.chb.2015.12.063.

Fernández-Ahumada, E. Montejo-Gámez, J., Sánchez-Zamora, P., Benlloch-González, M., Ortiz-Medina, L., Beato, M.C., Taguas, E.V. (2020). Development of professional skills in higher education: problem-based learning supported by immersive worlds. In L. Daniela (Ed.) New Perspectives on Virtual and Augmented Reality (in press). London; Routledge.

Göl, Ö., \& Nafalski, A. (2007). Collaborative learning in engineering education global. Journal of Engineering Education, 11(2), 173-180.

Grasso, D., \& Martinelli, D. (2010). Holistic Engineering. In D. Grasso \& M. Brown Burkin (Eds.), Holistic Engineering Educations: Beyond Technology. New York: Springer.

Hamari, J., Koivisto, J., \& Sarsa, H. (2014). Does gamification work? - A literature review of empirical studies on gamification. In Proceedings of the 47th Hawaii International Conference on System Sciences (pp.3025-3034).

Kasahara, R., Sakamoto, K., Washizaki, H., Fukazawa, Y. (2019). Applying Gamification to Motivate Students to Write High-Quality Code in Programming Assignments. In ITiCSE '19: Proceedings of the 2019 ACM Conference on Innovation and Technology in Computer Science Education (pp. 92-98). https://doi.org/https://doi.org/10.1145/3304221.3319792

Koivisto, J., \& Hamari, J. (2019). The rise of motivational information systems: A review of gamification research. International Journal of Information Management, 45, 191-210. https://doi.org/10.1016/j. ijinfomgt.2018.10.013 
Lecca, G., Petitdidier, M., Hluchy, L., Ivanovic, M., Kussul, N., Ray, N., \& Thieron, V. (2011). Grid computing technology for hydrological applications. Journal of Hydrology, 403(1-2), 186-199.

Nag, S., Katz, J. G., \& Saenz-Otero, A. (2013). Collaborative gaming and competition for CS-STEM education using SPHERES ZeroRobotics. Acta Astronautica, 83, 145-174.

Pertegal-Felices, M. L., Jimeno-Morenilla, A., Sánchez-Romero, J. L., \& Mora-Mora, H. (2020). Comparison of the effects of the kahoot tool on teacher training and computer engineering students for sustainable education. Sustainability. https://doi.org/10.3390/su12114778.

Randall, J. M., Morris, B. A., Wetzel, C. D., \& Whitehill, B. V. (1992). The effectiveness of Games for educational purposes: A review of recent research. Simulation \& Gaming, 23(3), 261-276.

Redel, M. D., Castillo, C., Aguilar, C., Polo, M. J., \& Taguas, E. V. (2014). Development of a virtual tool for learning basic organization and planning in rural engineering projects. European Journal of Engineering Education, 39(5), 507-517.

Remon, J., Hurst, G.A., Arauzo, J., 2020. Towards a Multicultural and Global Education Via International Co-Operation: British Chemists Working with Spanish Chemical Engineers on New Bio-Refinery Concepts, in: Chova, L.G., Martinez, A.L., Torres, I.C. (Eds.), 14th International Technology, Education and Development Conference (Inted2020). Iated-Int Assoc Technology Education \& Development, Valenica, pp. 9523-9528

Rodríguez-Donaire, S., \& Amante, B. (2012). Collaborative environments, a way to improve quality in Higher Education. Procedia - Social and Behavioral Sciences, 46, 875-884.

RossFitzgerald, A. M., M, E., \& Rhodes, D. H. (2014). Game-based for systems engineering concepts. Procedia - Computer Cience, 28, 430-440.

Rydakov, R., Nyashin, Y., Ilyalov, O., \& Podgaets, R. (2010). Problems of sport engineering in teaching theoretical mechanics. Procedia - Engineering 2, 2763-2768.

Sawilowsky, S. (2009). New effect size rules of thumb. Journal of Modern Applied Statistical Methods, 8(2), 467-474. https://doi.org/10.22237/jmasm/1257035100.

Schaf, F. M., Müller, D., Bruns, F. W., Pereira, C. E., \& Erbe, H. H. (2009). Collaborative learning and engineering workspaces. Annual Reviews in Control, 33, 246-252.

USDA Soil Conservation Service. (1972). National Engineering Handbook, Section 4, Hydrology. . Government Printing Office.

Uskov V.L., Bakken J.P., Penumatsa A., Heinemann C., Rachakonda R. (2018) Smart Pedagogy for Smart Universities. In: Uskov V., Howlett R., Jain L. (eds) Smart Education and e-Learning 2017. SEEL 2017. Smart Innovation, Systems and Technologies, vol 75. Springer, Cham

Venter, M. (2020). Gamification in STEM programming courses: State of the art. In 2020 IEEE Global Engineering Education Conference (EDUCON), (pp. 859-866). https://doi.org/https://doi.org/10.1109/ EDUCON45650.2020.9125395.

Wan Alwi, S. R., Yusof, K. M., Hashim, H., \& Zainon, Z. (2012). Sustainability Education for First Year Engineering Students using Cooperative Problem Based Learning. Procedia - Social and Behavioral Sciences, 56, 52-58.

Zhu, Z., Yu, M. \& Riezebos, P. (2016). A research framework of smart education. Smart Learning Environment 3 (4). https://doi.org/10.1186/s40561-016-0026-2

Publisher's Note Springer Nature remains neutral with regard to jurisdictional claims in published maps and institutional affiliations. 